\title{
Experimental and Numerical Study on the Heat Transfer Characteristics of a Newly-Developed Solar Active Thermal Insulation System
}

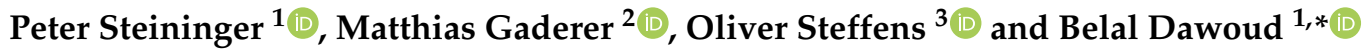 \\ 1 Laboratory of Advanced Energy and Building Systems, Faculty of Mechanical Engineering, \\ East Bavarian Technical University of Applied Sciences Regensburg (OTH Regensburg), \\ Prüfeninger Str. 58, 93049 Regensburg, Germany; peter2.steininger@oth-regensburg.de \\ 2 TUM Campus Straubing for Biotechnology and Sustainability, Chair of Regenerative Energy Systems, \\ Technical University of Munich, Schulgasse 16, 94315 Straubing, Germany; gaderer@tum.de \\ 3 Faculty of Applied Natural Sciences and Cultural Studies, \\ East Bavarian Technical University of Applied Sciences Regensburg (OTH Regensburg), \\ Seybothstr. 2, 93053 Regensburg, Germany; oliver.steffens@oth-regensburg.de \\ * Correspondence: belal.dawoud@oth-regensburg.de
}

Citation: Steininger, P.; Gaderer, M.; Steffens, O.; Dawoud, B.

Experimental and Numerical Study on the Heat Transfer Characteristics of a Newly-Developed Solar Active Thermal Insulation System. Buildings 2021, 11, 123. https://doi.org/10.3390/ buildings 11030123

Academic Editor: Zhenjun Ma

Received: 6 February 2021

Accepted: 15 March 2021

Published: 18 March 2021

Publisher's Note: MDPI stays neutral with regard to jurisdictional claims in published maps and institutional affiliations.

Copyright: (c) 2021 by the authors. Licensee MDPI, Basel, Switzerland. This article is an open access article distributed under the terms and conditions of the Creative Commons Attribution (CC BY) license (https:// creativecommons.org/licenses/by/ $4.0 /)$
Abstract: A newly-developed solar active thermal insulation system (SATIS) is introduced with the main objective to accomplish a highly-dependent total solar transmittance on the irradiation angle. SATIS is also designed to obtain the maximum transmittance at a prescribed design irradiation angle and to reduce it remarkably at higher irradiation angles. A purely mineral thermal insulation plaster with micro hollow glass spheres is applied to manufacture the investigated SATIS prototype Light-conducting elements (LCEs) have been introduced into SATIS and suitable closing elements have been applied. The SATIS prototype has been investigated both experimentally and numerically. It turned out that the contributions of conduction, radiation and convection to the effective thermal conductivity of SATIS, without the closing elements $\left(49 \frac{\mathrm{mW}}{\mathrm{mK}}\right)$, amount to $86.2 \%, 13.2 \%$ and $0.6 \%$, respectively. The angle-dependent short-wave radiation exchange within the LCE has been investigated via ray tracing. At the incidence angle of 19\% (design angle), $27 \%$ of the radiation within the LCE is absorbed by the absorber plate, resulting in measured and computed total solar energy transmittances of $11.2 \% / 11.7 \%$, respectively. For a typical summer irradiation angle of $60 \%, 98 \%$ of the incident radiation is absorbed by the surfaces at the entrance of the LCE. The corresponding total solar energy transmittance amounts to $2.9 \%$.

Keywords: solar active thermal insulation system (SATIS); experimental investigation; numerical simulation; effective thermal conductivity; ray tracing; angle-dependent total solar energy transmittance

\section{Introduction}

Being responsible for approximately $40 \%$ of total energy consumption and $36 \%$ of $\mathrm{CO}_{2}$ emissions [1], the building sector represents the largest energy consumer in Europe. Currently, about 35\% of the buildings in the EU are more than 50 years old, and nearly $75 \%$ of the building stock is highly energy-inefficient (Energy Performance Certificate D or E [2]). Depending on the country, only $0.4-1.2 \%$ of the building stock is renovated each year [3]. Following the EU Commission's impact assessment, there is a need for an average rate of renovation of 3\% annually to reach the EU's energy efficiency objectives in a cost-effective way. Every $1 \%$ increase in energy savings reduces gas imports by $2.6 \%$, so that the renovation of the existing building stock is of great importance [4].

The energy-efficient design of buildings has attracted, therefore, increasing attention as it contributes to the reduction of energy consumption and, consequently, to the related decrement of the emission of greenhouse gases. An increasing number of new materials 
and technologies are used to insulate buildings in order to reduce their energy consumption. In addition, building simulation tools are being more and more used in order to assess and improve the energy-saving potential of these new materials and technologies, examples of which are TRNSYS, ESP-r and EnergyPlus [5].

These tools use mathematical models to describe the physical processes taking place in buildings. If the building has an ordinary, well-known wall structure, these simulation tools can be used to make very precise predictions about the hygrothermal behavior of the building envelope using the built-in physical models. In the case of modified traditional facades, e.g., by incorporating transparent insulation materials (TIM) [6,7], more sophisticated models and simulation approaches are necessary, in order to consider the more complex physical phenomena [8]. In the particular case of applying TIMs, the transmission of irradiated solar energy through the system must be taken into account [9] together with the increased thermal resistance of the wall.

TIMs are mainly made of glass or plastic [10] and can be classified in the four categories: absorber-parallel, absorber-perpendicular, cavity and quasi-homogenous [6,7]. The achieved solar gain through TIMs very much reduce the transmission heat losses of the building, in some cases even provide a net positive heat gain into the building during wintertime. They are particularly suitable for the application on massive walls to make use of their heat storage capacity [11]. In addition, moisture damages in masonry can be eliminated by heat gain, which contributes to the preservation of the building substance. Furthermore, the solar heat gain increases the surface temperature of the internal walls, which allows the indoor air temperature to be reduced, thus achieving additional energy savings without making compromises concerning the comfortable indoor climate [12].

The main relevant performance indicators describing TIMs are the thermal conductance $(\Lambda)$ or U-value, as for conventional insulation systems, and, in addition, the transmittance $(\tau)$ or total solar energy transmittance $(g)$ [13]. The thermal conductance can be determined experimentally, for example, using a hot-plate apparatus. In [14], the effective thermal conductivities of four different polycarbonate TIMs were determined using different mean temperatures and inclination angles $\left(0^{\circ}, 45^{\circ}, 90^{\circ}\right)$. An increase in the effective thermal conductivity with increasing mean temperature of the sample was observed, but the influence of the inclination angle on the effective thermal conductivity of the investigated TIMs was negligible. Platzer's investigations on 11 different plastic honeycomb-type TIMs revealed also an increase in the effective thermal conductance with increasing mean temperature [15]. Furthermore, he developed and validated an analytical model based on experimental results, which includes the heat transport mechanisms conduction and long-wave thermal radiation, since the influence of convection was negligible for the examined structures.

For the determination of the solar transmittance of TIMs, integrating spheres and spectrophotometers are widely used. Čekon et al. [14] measured the spectral solar transmittance of four polycarbonate TIMs using a spectrophotometer and compared it with data derived from outdoor measurements. Platzer [16] used a similar setup to show that the experimentally determined solar transmittance of TIMs can be well reproduced by theoretical models. Symons [17] developed a new test bench incorporating an integrating sphere to study the angle-dependent solar transmittance of various planar TIMs. Here, he was able to achieve very good agreements with measurements recorded via spectrophotometer. For certain TIMs, like rectangular honeycomb or capillary structures, where the transmittance is quite high $(\approx 90 \%)$ and nearly constant over a wide range of incidence angles, analytical models were developed by Platzer [18] to correlate the angle-dependent transmittance with the angle of incidence. Good agreements were obtained with the experimental results. Such analytical functions can be included in building simulation software, though, they are only available for a limited number of TIMs [7]. Kuhn [19] described two methods for measuring the total solar energy transmittance in test bench studies that require either a cooled absorber plate or a cooled box. When determining $g$, not only solar transmittance is considered, but also the secondary heat transfer to the interior due to 
the transfer of absorbed solar radiation within the TIM to the inside surface. In order to conduct the experiments to determine $\tau$ and $g$, the angular dependence of the quantities must also be considered, hence, the integrating spheres are often mounted on rotatable disks [16], the samples can be inclined or the irradiation source (e.g., solar simulator) can be rotated $[17,19]$.

Świrska-Perkowska et al. [20] performed numerical simulations for an entire wall structure including a TIM. The introduced numerical model, which is developed for a honeycomb-type TIM made of modified cellulose acetate on a multi-layer wall, was used to predict monthly energy savings for different climatic conditions in Poland. The model was validated with results obtained through a methodology presented in the PN-EN ISO 13790:2008 standard for calculating monthly heat gains of opaque building elements. Čekon and Čurpek also investigated a multi-layer structure including a honeycomb-type TIM (PMMA) both experimentally using real weathering data and a test bench as well as numerically using EnergyPlus. The structure was investigated with a selective and a non-selective absorber between TIM and the external wall surface. It has been concluded that the high long-wave emissivity of the non-selective absorber resulted in a significantly reduced effective thermal resistance of the TIM [21]. In addition, a considerably reduced indoor air temperature was measured in the field tests during the heating season for the structure with the non-selective absorber [22]. This has been attributed to the associated high long-wave radiation losses to the ambient.

In [23], using the software RADIANCE and genBSDF, a ray-tracing methodology is applied to determine the optical properties and specifically the Bidirectional Scattering Distribution Function (BSDF) of a window system with and without a parallel slat transparent insulation material (PS-TIM). The BSDF was then prepared, via Window 7.4, for use in a building performance simulation using EnergyPlus to analyze the impact on window heat gains and losses as well as on the overall heating and cooling energy demand of the building. The concept underlying the BSDF can be described as a black box, where the inputs are any two angles, one for the incident beam and the other for the reflected beam at a given point on the surface. The output of the black box is the ratio between the incoming and outgoing radiant power for the given pair of angles.

The following drawbacks have been, however, reported on upon experimentally dealing with TIMs or applying them on building facades:

(a) In [7], it is concluded that glass honeycomb-type TIMs are fragile and thus not suitable for building applications.

(b) High cutting temperatures resulted in melting at the cut edges of plastic TIMs, which negatively affects their transparency [24].

(c) Solar transmittance of almost all experimentally investigated TIMs is almost constant over a wide range of incidence angles [6]. Accordingly, overheating problems are significant in summer due to excessive solar radiation absorption, either from a too large area of TI systems or large wall mass when applied to south-facing building facades $[6,24,25]$.

(d) Plastic-based TIMs represent a potential fire hazard, when attached to facades of high-rise buildings [26].

(e) Mechanical shading devices used to overcome the overheating problems mentioned in (c) are susceptible to failure and therefore require frequent and expensive maintenance $[6,27]$.

(f) The fragile structure of silica aerogel-based TIMs is one of the main problems that has prevented their wider application. It was not straightforward to fabricate large crack-free pieces of monolithic silica aerogels and the maximum size was limited to $0.6 \mathrm{~m} \times 0.6 \mathrm{~m}$. Accordingly, monolithic silica aerogel-based TIMs have only been used in research [28].

(g) According to [10], most of the TIMs available on the market are made of plastic or glass. This implies that the thermal conductivity of the base material is much higher compared to conventional thermal insulation materials, which leads to ex- 
cessive thermal losses during off-shine periods. In particular, plastic-based TIMs shall be associated with intensive efforts concerning their disposal upon recycling the building materials.

To mitigate most of the mentioned drawbacks of TIMs, this work introduces a proofof-concept prototype of a newly-developed solar active thermal insulation system (SATIS), with which the transmittance shall attain its maximum value at a desired solar irradiation angle (e.g., solar noon angle in wintertime) and sharply decreases at higher irradiation angles to reduce the overheating potential in summertime. SATIS differs from previous developments of TIMs [10] on both material used and geometric structure. In contrast to the commonly used plastic and glass-based TIMs, a new type of purely mineral thermal insulation plaster is used as the base material, which contains micro hollow glass spheres as additives [29]. Due to the partial vacuum inside the micro hollow glass spheres and the high porosity of the plaster [30], a thermal conductivity of the thermal insulation plaster of $0.044 \frac{\mathrm{W}}{\mathrm{mK}}$ is reached [31], which is far below that of glass and plastic. It is expected, therefore, that the thermal losses during off-shine periods will be very much reduced compared to those of TIMs. The disposal of the applied base material in SATIS is much easier compared to plastic-based TIMs. To meet the design objectives of SATIS, the described mineral insulation plaster is equipped with light-conducting elements (LCEs), which are incorporated at a specific inclination angle to the horizontal. Those LCEs consist of cylindrical, air-filled stepped holes, which are-in the first prototype investigated in this work-closed with borosilicate glass cylinders on the outside surface of the wall. The non-directional reflection of the comparatively rough surface within the holes is intended to limit the range of radiation transport through SATIS, compared to the nearly constant transmittance of other TIMs over a wide range of incidence angles [6], to a defined range of angles for winter months, so that overheating can be avoided at higher sun elevations in summer. Accordingly, the required shading devices for TIMs, along with their installation and maintenance costs, can be avoided.

To evaluate the performance indicators of SATIS; namely, the effective thermal conductivity and the total solar energy transmittance, a thorough steady-state experimental investigation of the heat transfer characteristics of the basic insulation panel to produce SATIS before introducing the LCE (state 1), the insulation panel with the LCE (state 2) and the final SATIS by closing the LCE with the borosilicate glass cylinders (state 3) has been conducted. This measurement campaign resulted in the effective thermal conductivities of all three states. Moreover, a thermal and radiative simulation model is developed and validated for SATIS using the simulation software COMSOL Multiphysics ${ }^{\circledR}$. A ray-tracing approach is used to compute the short-wave radiation transport within the LCEs of SATIS. Comparing the experimental and simulation results enables to define the order of magnitude of the contribution of each heat transfer mechanism in the measured effective thermal conductivity. Finally, using the computed radiation distribution, the angle-dependent total solar energy transmittance is determined and compared with that derived from the experiments. In our next step of development, the validated simulation model will be applied to optimize the SATIS design. Furthermore, the optimized design will be upscaled to investigate the SATIS effect on reducing the transmission heat losses of a real building over a complete heating season based on real weathering data.

\section{Materials and Methods}

The following subsections introduce the SATIS concept and present the experimental setup, i.e., the structure of the investigated SATIS prototype test specimen, the test bench as well as the test procedure and conditions. Afterwards, the numerical models for computing the heat and radiation transport within SATIS are extensively described. 


\subsection{SATIS Concept}

The SATIS concept is supposed to be an alternative to the glass- and plastic-based TIMs, whose maximum transmittance takes place at horizontal irradiation and which show a nearly constant solar transmittance over a wide range of incidence angles $[6,10]$. Therefore, the following objectives were defined for the development of SATIS:

1. To achieve maximum solar radiation transmittance at a defined angle of incidence typical for winter months or the transitional season.

2. To considerably reduce solar transmittance at high summer irradiation angles to prevent summer overheating.

3. To have an effective thermal conductivity compared to conventional thermal insulation materials (e.g., foamed plastics or mineral fiber insulation) in order to maintain a high thermal resistance during nighttime and cloudy periods.

4. To develop a purely mineral, location-adaptable product that is readily recyclable and does not cause future disposal problems.

\subsection{Experimental Setup}

In this subsection, the structure of the SATIS test specimen will be described. Furthermore, the test bench, consisting of a differential climatic chamber, a solar simulator and a sample holder as well as the test procedure and conditions are presented.

\subsubsection{Test Specimen}

The SATIS' proof of concept prototype, which is manufactured and investigated in this study, consists of the recently launched purely mineral thermal insulation plaster maxit eco72 [29,30] and light-conducting elements (LCEs), which are incorporated in the plaster. In this study, the thermal insulation plaster is brought into a panel form having a cross-sectional area of $300 \mathrm{~mm} \times 300 \mathrm{~mm}$ and a typical insulation thickness of $80 \mathrm{~mm}$. To produce the panel prototype, the insulating plaster is inserted into a mold until it has been dried. Afterwards, stepped holes with diameters of $6 \mathrm{~mm}$ and $8 \mathrm{~mm}$ are drilled into the insulation panel at an inclination angle of $19^{\circ}$ to the surface normal, using a CNC processing machine. The inclination angle of $19^{\circ}$ was chosen because it corresponds to a typical noon sun elevation during the winter months in southern Germany. For high sun summer positions, the system will provide sufficient protection against overheating. The two different hole diameters were chosen to create seats for the closure elements of the light-conducting holes. The $8 \mathrm{~mm}$ holes have $26.4 \%$ share on the front surface area, those with $6 \mathrm{~mm}$ have a share of $14.9 \%$ on the back surface. A constant distance of $5 \mathrm{~mm}$ is maintained between the holes on the outside surface. This was achieved via an offset arrangement of the holes. In a last step, an exterior paint [32] is applied to the outer surface.

Figure 1a shows the manufactured panel prototype of SATIS in front view. The introduced prototype construction in this development stage focuses mainly on providing a proof of concept rather than developing an automated manufacturing process. The light-conducting elements are closed with solid cylinders made of borosilicate glass $(8 \mathrm{~mm}$ diameter, $20 \mathrm{~mm}$ length), which have a transmittance of approximately $90 \%$ in the visible and near infrared range [33]. The cylinders are melted on both ends, having been cut to a length of $20 \mathrm{~mm}$, so that the glass turbidity at the cut surfaces is removed. Figure $1 \mathrm{~b}$ illustrates the completed SATIS, which consists entirely of mineral components (objective 4 in Section 2.1). The structure of SATIS is shown in isometric as well as front and sectional view with the nominal lengths in the Figure 1c,d. 


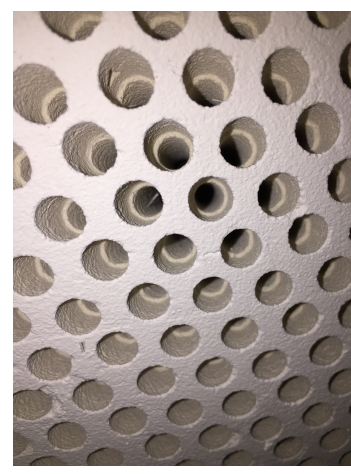

(a)

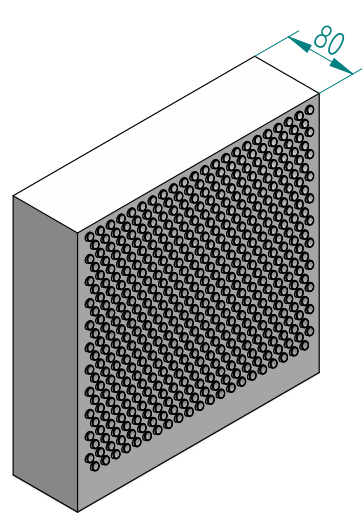

(c)

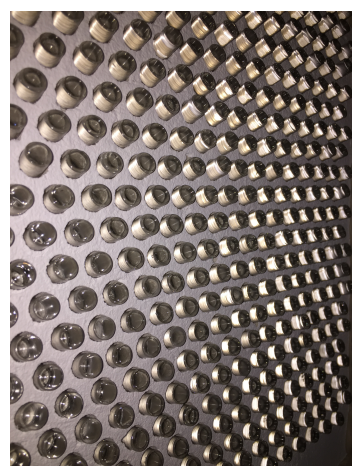

(b)
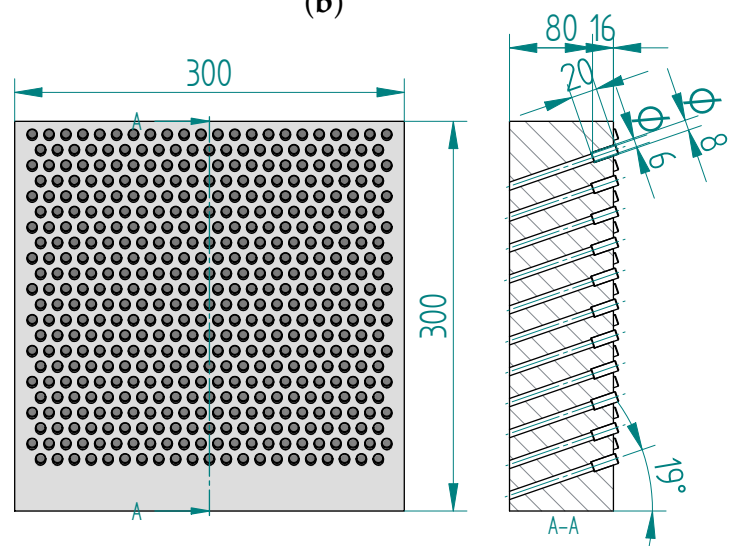

(d)

Figure 1. Solar active thermal insulation system (SATIS). (a) Front view of the manufactured panel prototype of SATIS (state 2). (b) Panel of SATIS closed on the outside surface with borosilicate glass cylinders (state 3). (c) Isometric view of SATIS. The nominal length given is in millimeters. (d) Front (left) and sectional (right) view of SATIS. The stepped holes are closed on the outside surface with borosilicate glass cylinders. The nominal lengths given are in millimeters.

\subsubsection{Test Bench}

Figure 2a shows schematically the test bench and its components, which are used to investigate SATIS. This test bench and the measurement devices have already been described in detail in [31], so that only a brief summary will be given here.

The differential climatic chamber (cf. Figure $2 b$ ) consists of an outdoor and indoor zone, in which the air temperatures $\left(T_{\mathrm{OC}}, T_{\mathrm{IC}}\right)$ and relative humidities $\left(\varphi_{\mathrm{OC}}, \varphi_{\mathrm{IC}}\right)$ can be adjusted. By means of a solar simulator (cf. Figure 2c), which is located in the outdoor zone, variable sun positions can be adjusted with different radiation intensities $\left(I_{S, \perp}\right)$ and angles of incidence $(\varphi)$. In the partition wall between the two zones, there is a sample holder (cf. Figure 2d), in which the SATIS prototype is placed for investigating the heat and radiation transport. This sample holder consists of multilayer insulation to minimize the edge effects due to the small size of the test specimen. 


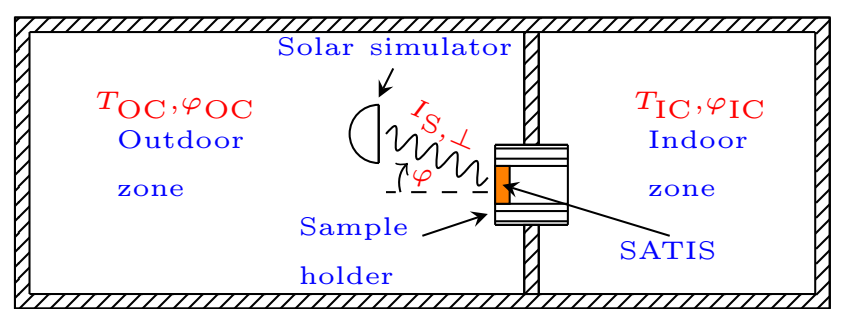

(a)

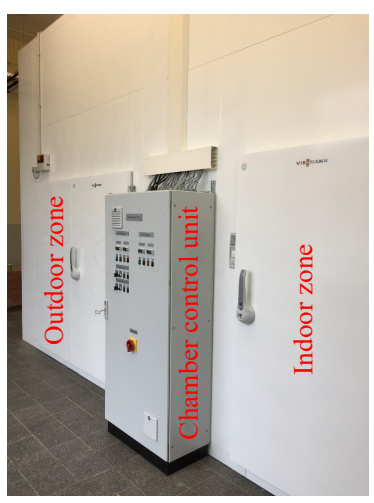

(b)

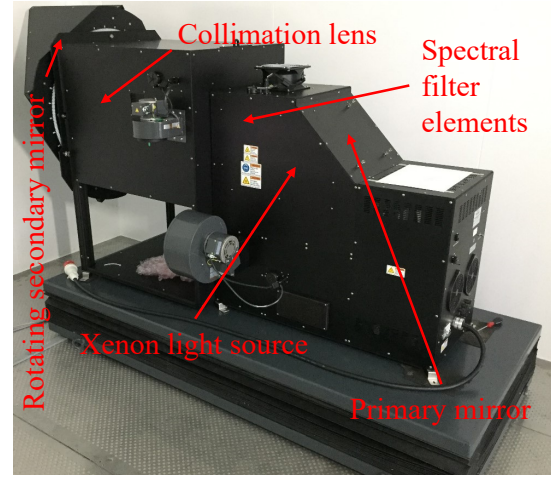

(c)

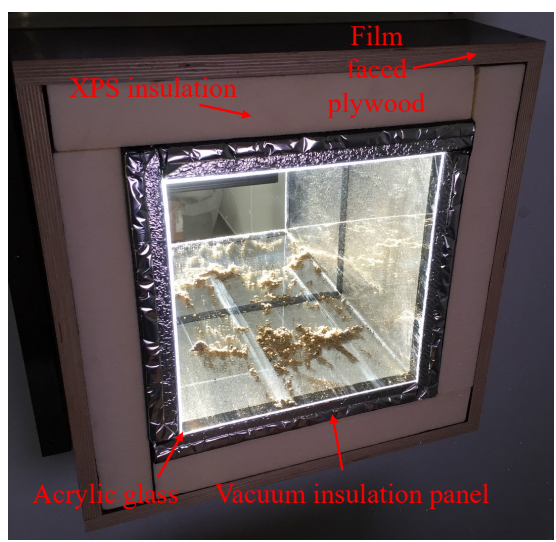

(d)

Figure 2. Illustration of the differential climatic chamber, consisting of an indoor and an outdoor zone $(\mathbf{a}, \mathbf{b})$, the solar simulator (c) and the sample holder (d). (a) Schematic representation of the experimental setup for investigating SATIS. (b) Front view from the outside of the differential climatic chamber. (c) Solar simulator in the outdoor zone. (d) Sample holder consisting of a multi-layer insulation.

\subsubsection{Test Procedure and Conditions}

The test procedures and conditions, which were used to determine the effective thermal conductivity and the total solar energy transmittance of SATIS, will be described in this subsection.

\section{Effective Thermal Conductivity}

In the tests carried out, the effective thermal conductivity $\left(\lambda_{\text {eff }}\right)$ of SATIS was determined step-by-step by measuring the SATIS panel at different stages during manufacture. A panel was investigated in its original state before machining with the CNC processing machine (state 1, cf. Figure 3a), after drilling the holes (state 2, cf. Figure 3b) and after placing the glass cylinders in the light-conducting elements (state 3, cf. Figure 3c). For states 1 and 2 , the respective panel is mounted in the sample holder and covered from both sides with $4 \mathrm{~mm}$ steel plates with negligible thermal resistances (cf. Figure 3d), which are used for temperature homogenization and for mounting the sensor system [31], consisting of heat flow measuring plates and temperature sensors with measurement uncertainties of $\pm 5 \%$ and $\pm 0.03^{\circ} \mathrm{C}$, respectively. By using two heat flow measuring plates, the one-dimensional nature of the measured heat flux through SATIS can be assessed. The maximum deviation of the one-dimensionality of the heat flux was 3.3\% for all measurements and $2.6 \%$ on average, which is below the measurement uncertainty of the heat flow measuring plates $( \pm 5 \%)$. For states 1 and 2, the thermal conductance was calculated according to Equation (1).

$$
\lambda_{\mathrm{eff}}=\frac{\left(\dot{q}_{\mathrm{IS}}+\dot{q}_{\mathrm{OS}}\right) / 2}{T_{\mathrm{IS}}-T_{\mathrm{OS}}} \delta
$$


Here, $\dot{q}_{\mathrm{IS}}$ and $\dot{q}_{\mathrm{OS}}$ or $T_{\mathrm{IS}}$ and $T_{\mathrm{OS}}$ denote the measured steady-state heat fluxes or temperatures on the steel plates on the inside (IS) and outside (OS) surfaces, respectively. $\delta$ is the thickness of the produced panel and amounts to $(80 \pm 2) \mathrm{mm}$. The measurement uncertainty of $\lambda_{\text {eff }}$ is calculated on the basis of the Gaussian law of error propagation [34]. For each state, measurements were performed for three temperature differences (cf. Table 1) between the outdoor and indoor zones, in order to also take into account nonlinearities in natural convection or thermal radiation within the LCEs.

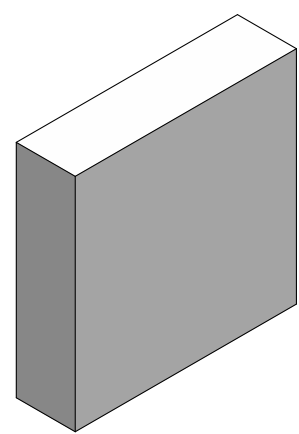

(a)

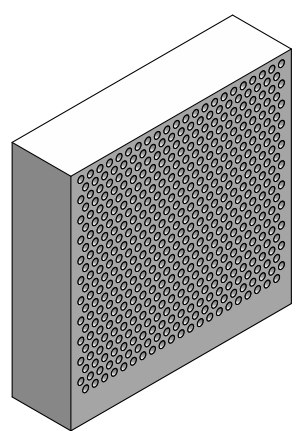

(b)

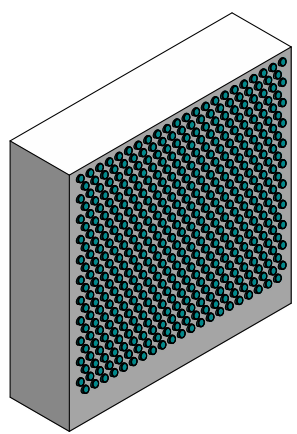

(c)

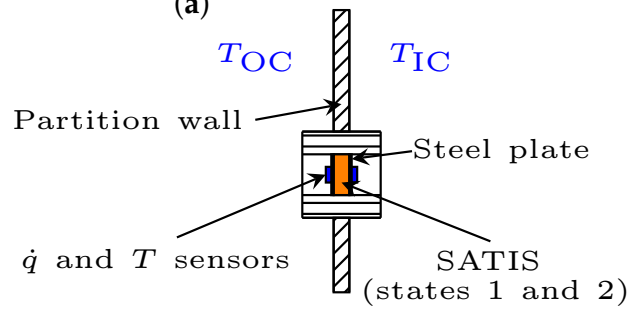

(d)

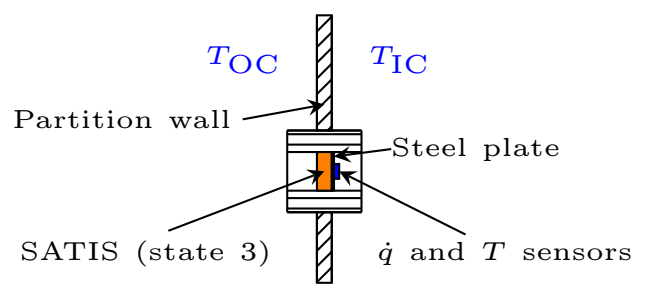

(e)

Figure 3. SATIS prototype in the manufacturing states 1,2 and 3 and the experimental setups. (a) SATIS manufacturing state 1. (b) SATIS manufacturing state 2. (c) SATIS manufacturing state 3. (d) Setup for the experimental investigation of SATIS in states 1 and 2. (e) Setup for the experimental investigation of SATIS in state 3.

Due to the protruding glass cylinders on the outside surface of SATIS in state 3, no steel plate or measuring devices could be mounted there, so that only the temperature $\left(T_{\text {IS }}\right)$ and heat flux ( $\left.\dot{q}_{\text {IS }}\right)$ on the inside surface could be measured (cf. Figure 3e). Moreover, since the temperature on the outside surface of SATIS ( $T_{\mathrm{OS}}$ ) cannot be measured, the determination of the effective thermal conductivity according to Equation (1) is not possible.

In the steady state, having a constant surface temperature difference $\left(T_{\mathrm{IS}}-T_{\mathrm{OS}}\right)$, the thermal conductivity of SATIS is directly proportional to the heat flux according to Equation (2).

$$
\lambda=\underbrace{\frac{\delta}{T_{\mathrm{IS}}-T_{\mathrm{OS}}}}_{\text {const. }} \dot{q} \rightarrow \lambda \sim \dot{q}
$$

As listed in Table 1, almost the same air temperature differences between both chambers $\left(\Delta T_{\mathrm{IC}-\mathrm{OC}}\right)$ were measured in each manufacturing state of SATIS (e.g., $1-\exp .1$ and 2 -exp. 1, etc.). Assuming a negligible change of the convective heat transfer coefficient on each side of the SATIS sample, the temperature difference between air and surface temperatures shall be equal for each corresponding experiment (exp. 1, exp. 2 or exp. $3)$. Accordingly, the surface temperature difference $\left(T_{\mathrm{IS}}-T_{\mathrm{OS}}\right)$ shall be constant in each experiment, thus fulfilling the condition in Equation (2). It follows that the thermal conductivity is in a good approximation proportional to the heat flux. The effective thermal conductivity of SATIS in state 3 can, therefore, be determined by scaling the effective 
thermal conductivity of states 1 and 2 with the measured heat fluxes on the inside surface of state 3 and subsequent averaging according to Equation (3).

$$
\lambda_{\mathrm{eff}, 3}=\left(\frac{\dot{q}_{\mathrm{IS}, 3}}{\dot{q}_{\mathrm{IS}, 2}} \lambda_{\mathrm{eff}, 2}+\frac{\dot{q}_{\mathrm{IS}, 3}}{\dot{q}_{\mathrm{IS}, 1}} \lambda_{\mathrm{eff}, 1}\right) / 2
$$

Table 1. Mean measured indoor $\left(T_{\mathrm{IC}}\right)$ and outdoor $\left(T_{\mathrm{OC}}\right)$ air temperatures as well as the absolute temperature differences $\left(\Delta T_{\mathrm{IC}-\mathrm{OC}}\right)$ for the experiments.

\begin{tabular}{lccc}
\hline SATIS State & $\boldsymbol{T}_{\mathbf{I C}}$ in ${ }^{\circ} \mathrm{C}$ & $\boldsymbol{T}_{\mathbf{O C}}$ in ${ }^{\circ} \mathrm{C}$ & $\Delta \boldsymbol{T}_{\mathbf{I C}-\mathrm{OC}}$ in $\mathrm{K}$ \\
\hline 1-exp. 1 & 19.0 & -0.7 & 19.7 \\
1-exp. 2 & 23.7 & -5.6 & 29.3 \\
1-exp. 3 & 28.3 & -10.6 & 38.9 \\
\hline 2-exp. 1 & 19.0 & -0.6 & 19.6 \\
2-exp. 2 & 23.7 & -5.4 & 29.1 \\
2-exp. 3 & 28.3 & -10.6 & 38.9 \\
\hline 3-exp. 1 & 19.0 & -0.4 & 19.4 \\
3-exp. 2 & 23.6 & -5.2 & 28.8 \\
3-exp. 3 & 28.3 & -10.3 & 38.6 \\
\hline
\end{tabular}

Total Solar Energy Transmittance

The total solar energy transmittance, which consists of the direct solar transmittance and the secondary internal heat transfer factor including thermal radiation and convective heat transfer, was determined for SATIS in state 3 (cf. Figure 3c), i.e., the complete assembly including the borosilicate glass cylinders. SATIS was measured calorimetrically under the air temperatures proposed in [35] $\left(T_{\mathrm{IC}}=T_{\mathrm{OC}}=20^{\circ} \mathrm{C}\right)$. The methodologies described by Kuhn [19], which involve the use of a cooled absorber plate or cooled box, provide two options for determining the total solar energy transmittance.

In this work, a new methodology, which was developed for the test bench presented in Section 2.2.2, is used to determine the total solar energy transmittance. Figure 4 shows schematically the employed experimental setup. The absorber plate, which was painted black, was mounted on the inside surface of SATIS in exactly the same way as in the investigations to measure the effective thermal conductivity. The black-painted steel plate was also equipped with a heat flow measuring plate and a temperature sensor. During the experiment, the irradiation through the solar simulator at different defined incidence angles $(\varphi)$ and with a defined radiation intensity on a surface perpendicular to the direction of irradiation $\left(I_{S, \perp}\right)$ is carried out until the investigated sample reaches a steady state.

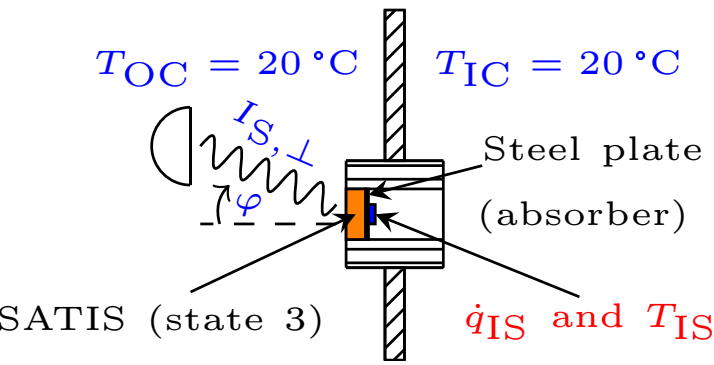

Figure 4. Experimental setup for the determination of the angle-dependent total solar energy transmittance.

Using the measured steady state heat flux ( $\left.\dot{q}_{\mathrm{IS}}\right)$ and temperature $\left(T_{\mathrm{IS}}\right)$ on the steel plate, an energy balance is performed according to Equation (4).

$$
\dot{q}_{\mathrm{IS}}=g_{\exp } I_{\mathrm{S}, \perp}-\left(T_{\mathrm{IS}}-T_{\mathrm{OC}}\right) / \sum R_{\mathrm{th}}
$$


In Equation (4), $g_{\exp }$ denotes the experimentally determined total solar energy transmittance. $\sum R_{\mathrm{th}}$, which is calculated according to Equation (5), includes the sum of the thermal resistances between the plate and the air in the outdoor chamber.

$$
\sum R_{\mathrm{th}}=\underbrace{\frac{\delta}{\lambda_{\text {eff,3 }}}}_{\text {SATIS }}+\underbrace{\frac{1}{h_{\mathrm{OC}}}}_{\text {Air }}
$$

Solving Equation (4) for $g_{\exp }$ yields Equation (6).

$$
g_{\exp }=\frac{\dot{q}_{\mathrm{IS}}+\overbrace{\left(T_{\mathrm{IS}}-T_{\mathrm{OC}}\right) / \sum R_{\mathrm{th}}}^{\text {Heat loss to the outdoor zone }}}{I_{\mathrm{S}, \perp}}
$$

In Equation (5), $h_{\mathrm{OC}}$ is set to $14 \frac{\mathrm{W}}{\mathrm{m}^{2} \mathrm{~K}}$ based on experimental results obtained in previous test bench investigations [31], since this quantity cannot be determined for SATIS in state 3 (protruding glass cylinders on the outside surface of the sample). An analysis in Equation (6) shows that the relative change in $g_{\exp }$ amounts to only $0.3 \%$ when $h_{\mathrm{OC}}$ is halved $\left(7 \frac{\mathrm{W}}{\mathrm{m}^{2} \mathrm{~K}}\right)$ or doubled $\left(28 \frac{\mathrm{W}}{\mathrm{m}^{2} \mathrm{~K}}\right)$, i.e., $h_{\mathrm{OC}}$ has only a minor effect on the experimentally determined total solar energy transmittance.

Since SATIS is a highly angle-dependent system, the experiments to determine $g_{\exp }$ were conducted in a narrow range around the design angle of $19^{\circ}$ and, as the incidence angle $(\varphi)$ increased, the distance between the investigated irradiation angles was widened. Table 2 shows the investigated angles of incidence and the measured solar radiation intensities on a surface perpendicular to the direction of irradiation. The radiation intensities were measured at the beginning of each experiment by a solar reference cell $( \pm 3 \%)$ delivered by the solar simulator's manufacturer. The reference cell consists of a $20 \mathrm{~mm} \times 20 \mathrm{~mm}$ photovoltaic cell encased in a metal enclosure with a protective window and a temperature sensor.

Table 2. Investigated angles of incidence $(\varphi)$ and measured solar radiation intensities on a surface perpendicular to the direction of irradiation $\left(I_{S, \perp}\right)$ for SATIS in state 3 .

\begin{tabular}{lclc}
\hline$\varphi$ in $^{\circ}$ & $\boldsymbol{I}_{\mathbf{S}, \perp}$ in $\frac{\mathbf{W}}{\mathbf{m}^{2}}$ & $\varphi$ in ${ }^{\circ}$ & $\boldsymbol{I}_{\mathbf{S}, \perp}$ in $\frac{\mathbf{W}}{\mathbf{m}^{2}}$ \\
\hline 0 & 1070 & 24 & 1090 \\
14 & 1110 & 30 & 1100 \\
17 & 1100 & 35 & 1060 \\
19 & 1060 & 45 & 1040 \\
21 & 1090 & 60 & 940 \\
\hline
\end{tabular}

\subsection{Numerical Modeling}

The numerical study of SATIS is performed for state 2 (drilled panel) and state 3 (drilled panel with borosilicate glass cylinders). The reason for not modeling state 1 , in which only heat conduction is present, is that the simulation does not provide any new knowledge, since the effective thermal conductivity in this state corresponds to the thermal conductivity of the thermal insulation plaster $\left((45 \pm 2) \frac{\mathrm{mW}}{\mathrm{mK}}\right)$ as will be presented in Section 3.1. For state 2, an investigation is carried out with regard to the effective thermal conductivity, taking into account natural convection (fluid flow) and long-wave radiative heat transfer within the LCEs. For state 3 , the effective thermal conductivity is also determined, but in addition, the short-wave radiation transport is modeled using a ray-tracing approach to compare the calculated total solar energy transmittances with the experimental $g$. 


\subsubsection{Thermal and Fluid Flow Modeling}

Figure $5 \mathrm{a}, \mathrm{b}$ show the geometries of the simulation models of SATIS in state 2 and state 3 , respectively. In each case, the simulation model consists of one inclined LCE $\left(19^{\circ}\right.$ to the horizontal) to reduce the computational effort. A square cross-sectional area of the models was chosen as a compromise to best account for the influences of the LCEs located in the center (six neighbors) and at the edges (2-3 neighbors), which are superimposed on the very well heat-conducting absorber surface. The models have the same area fraction of the stepped hole on the front and back surface as the test specimen $(26.4 \%$ and $14.9 \%$, cf. Section 2.2.1). The assignment of the numbers in Figure $5 b$ to the respective materials is given in Table 3. The computational domain (5) is only needed as an inlet domain for the calculation of the short-wave radiation transport by ray tracing and will be explained in detail later on. In addition, Table 3 shows the thermal boundary conditions, indicated by the colored frames, which are applied to the front faces of each model. The heat transfer coefficient on the inside surface $\left(h_{\mathrm{IC}}\right)$ was determined in the steady-state using Newton's law of heat transfer according to Equation (7) and amounts to $12 \frac{\mathrm{W}}{\mathrm{m}^{2} \mathrm{~K}}$ on average.

$$
h_{\mathrm{IC}}=\frac{\dot{q}_{\mathrm{IS}}}{T_{\mathrm{IS}}-T_{\mathrm{IC}}}
$$

On the outside surface $\left(h_{\mathrm{OC}}\right.$ ), a value of $14 \frac{\mathrm{W}}{\mathrm{m}^{2} \mathrm{~K}}$ (cf. Section 2.2.3) is used. The four side surfaces of the models are provided with adiabatic boundary conditions $(-\boldsymbol{n} \cdot \dot{\boldsymbol{q}}=0)$ to establish a one-dimensional heat flux.

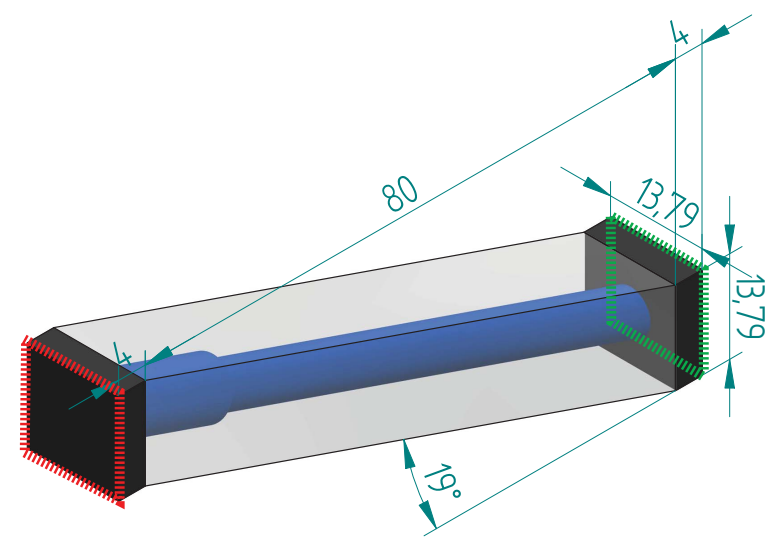

(a)

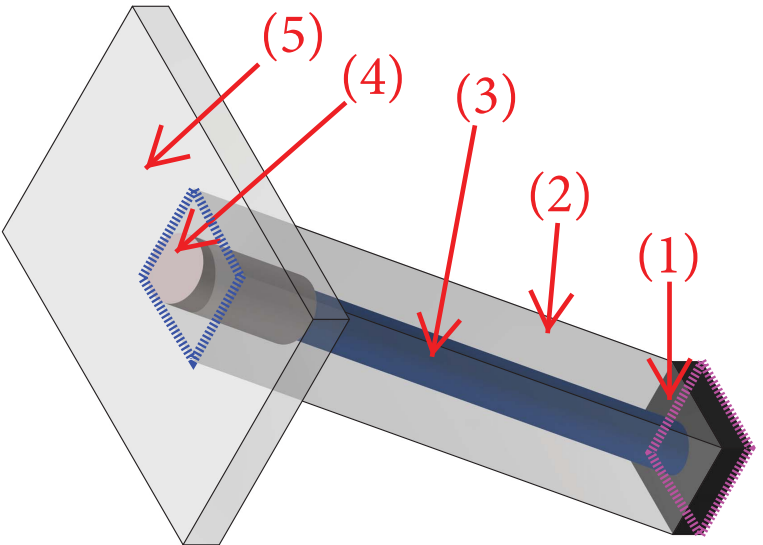

(b)

Figure 5. Geometries of the investigated SATIS models in state 2 and state 3. (a) Geometry of the SATIS model in state 2. The nominal lengths given are in millimeters. (b) Geometry of the SATIS model in state 3. Assignment of numbers (1) through (5) to the materials and their properties is listed in Table 3.

Table 3. The materials, material properties and boundary conditions used for the SATIS models in state 2 and state 3 .

\begin{tabular}{|c|c|c|c|c|c|c|}
\hline No. & Material & $\lambda$ in $\frac{W}{\mathrm{~m} \mathrm{~K}}$ & $\rho$ in $\frac{\mathrm{kg}}{\mathrm{m}^{3}}$ & $c_{p}$ in $\frac{\mathrm{J}}{\mathrm{kg} \mathrm{K}}$ & $n$ & Reference \\
\hline (1) & Steel & 31 & 7870 & 435 & - & [36] \\
\hline (2) & Thermal insulation plaster & 0.045 & 125 & 1150 & - & {$[29,31]$} \\
\hline (3) and (5) & Air (COMSOL ref. material) & $\lambda(T)$ & $\rho(T)$ & $c_{p}(T)$ & 1 & [37] \\
\hline (4) & Borosilicate glass & 1.2 & 2230 & 830 & 1.473 & [33] \\
\hline & Frame color & \multicolumn{2}{|c|}{ Red } & \multicolumn{3}{|c|}{ Green } \\
\hline & $\begin{array}{l}\text { Boundary condition } \\
\text { Frame color }\end{array}$ & \multicolumn{2}{|c|}{$\begin{array}{c}T_{\mathrm{OS}}=\text { const. } \\
\text { Blue }\end{array}$} & \multicolumn{3}{|c|}{$\begin{array}{c}T_{\text {IS }}=\text { cons } \\
\text { Violet }\end{array}$} \\
\hline & Boundary condition & \multicolumn{2}{|c|}{$-\boldsymbol{n} \cdot \dot{\boldsymbol{q}}=h_{\mathrm{OC}}\left(T_{\mathrm{OC}}-T_{\mathrm{OS}}\right)$} & \multicolumn{3}{|c|}{$\begin{array}{c}g: \frac{\lambda_{\text {eff }}: T_{\mathrm{IS}}=\text { const. }}{\boldsymbol{n} \cdot \dot{\boldsymbol{q}}=h_{\mathrm{IC}}\left(T_{\mathrm{IC}}-T_{\mathrm{IS}}\right)}\end{array}$} \\
\hline
\end{tabular}


The steady state heat transport including conduction, convection and thermal radiation in the computational domains (cf. Figure $5 a, b$ ) is modeled via Equation (8).

$$
\rho c_{p} \boldsymbol{u} \cdot \nabla T=-\nabla \cdot\left(\dot{\boldsymbol{q}}+\dot{\boldsymbol{q}}_{r}\right)
$$

Here, $\rho$ denotes density, $c_{p}$ specific heat capacity, $u$ vector of velocity, $\nabla$ nabla operator, $T$ temperature, $\dot{\boldsymbol{q}}$ vector of heat flux by conduction and $\dot{\boldsymbol{q}}_{\boldsymbol{r}}$ vector of heat flux by long-wave radiation. In state 3 , the LCEs are closed on the outside surface with borosilicate glass cylinders. Together with the small diameter of such closed LCEs, which have a low inclination to the horizontal $\left(19^{\circ}\right)$, the influence of convection is expected to be quite small. These expectations are going to be quantified and discussed in Section 3. The Fourier law in Equation (9) states that the heat flux by conduction is directly proportional to the temperature gradient $(\nabla T)$, whereas the proportionality constant is the thermal conductivity $\lambda$.

$$
\dot{q}=-\lambda \nabla T
$$

According to the Stefan-Boltzmann law, the area-specific radiant power $\left(e_{b}(T)\right)$ of a black-body emitted over all wavelengths is determined by Equation (10) and depends on the fourth power of the temperature.

$$
e_{b}(T)=n^{2} \sigma T^{4}
$$

$\sigma$ denotes the Stefan-Boltzmann constant $\left(5.67 \times 10^{-8} \mathrm{~W} / \mathrm{m}^{2} / \mathrm{K}^{4}\right)$ and $n$ the refractive index. The inward radiative heat flux $\left(-\boldsymbol{n} \cdot \dot{\boldsymbol{q}}_{r}\right)$ is obtained according to Equation (11) from the difference between absorbed incident $(\alpha G)$ and emitted $\left(\varepsilon e_{b}(T)\right)$ radiant power, whereas for gray and diffuse radiating opaque surfaces the relation given by Equation (12) is applicable.

$$
\begin{gathered}
-\boldsymbol{n} \cdot \dot{\boldsymbol{q}}_{r}=\varepsilon\left(G-e_{b}(T)\right) \\
\alpha=\varepsilon=1-\rho
\end{gathered}
$$

The mathematical description of the fluid flow is done with the equations of conservation of mass and momentum in Equations (13) and (14). $p, \mu, I$ and $f$ denote pressure, dynamic viscosity, identity matrix and vector of volume forces. The surfaces within the LCE are provided with no-slip boundary conditions.

$$
\begin{gathered}
\boldsymbol{\nabla} \cdot(\rho \boldsymbol{u})=0 \\
\rho \boldsymbol{u} \cdot \nabla \boldsymbol{u}=-\nabla p+\nabla \cdot\left[\mu\left(\boldsymbol{\nabla} \boldsymbol{u}+(\boldsymbol{\nabla} \boldsymbol{u})^{\top}\right)-\frac{2}{3} \mu(\boldsymbol{\nabla} \cdot \boldsymbol{u}) \boldsymbol{I}\right]+\boldsymbol{f}
\end{gathered}
$$

\subsubsection{Short-Wave Radiation Transport Modeling}

Concerning the short-wave radiation transport, it is only computed in the domains (3)-(5) using a ray tracing approach. The radiation, which strikes the surfaces bordering these domains and is absorbed there, is considered a heat flux boundary condition according to Equation (15).

$$
-n \cdot \dot{\boldsymbol{q}}=\dot{q}_{b}
$$

The boundary heat flux $\dot{q}_{b}$ at a discretized surface element is calculated by the absorbed radiation power of all rays striking this surface element. The radiation transport is modeled using a ray-tracing approach, in which the electric field $E$ of an electromagnetic wave can be written in the form of Equation (16) [38].

$$
E=a \mathrm{e}^{i \chi}
$$


Here, $\boldsymbol{a}$ denotes the amplitude and $\chi$ the phase, which depends on the position vector $r$ and time $t$. Assuming that the field is observed only at locations positioned very far from any source, phase $\chi$ can be expressed as stated in Equation (17).

$$
\chi=v \cdot r-\omega t+\gamma
$$

In Equation (17), $v$ is the wave vector, $\omega$ the angular frequency and $\gamma$ an arbitrary phase shift. The angular frequency and the wave vector are further related in an isotropic medium by Equation (18).

$$
\omega=\frac{c|v|}{n(\boldsymbol{r})}
$$

Here, $c$ denotes the speed of light and $n(r)$ is the refractive index of the medium, which is listed for borosilicate glass and air in Table 3. Consequently, the wave vector and the angular frequency can be expressed in terms of the phase according to Equation (19).

$$
v=\frac{\partial \chi}{\partial r} \quad \omega=-\frac{\partial \chi}{\partial t}
$$

Using the analogy of [39], it follows that the ray trajectory can be computed by solving six coupled first-order differential equations for the components of $v$ and $r$ according to Equation (20).

$$
\frac{\mathrm{d} v}{\mathrm{~d} t}=-\frac{\partial \omega}{\partial r} \quad \frac{\mathrm{d} r}{\mathrm{~d} t}=\frac{\partial \omega}{\partial v}
$$

In regions of constant refractive index $n$, the simplified equations are given in Equation (21).

$$
\frac{\mathrm{d} v}{\mathrm{~d} t}=\mathbf{0} \quad \frac{\mathrm{d} r}{\mathrm{~d} t}=\frac{c v}{n|v|}
$$

Figure 6 illustrates the domains of the SATIS model in state 3, which participate in the short-wave radiation transport. The main boundary conditions for the computation of the radiation transport, which are listed in Table 4, are labeled in this figure. For all other boundaries that border the domains (3)-(5), a material discontinuity boundary condition is applied. The radiation emitted at the ray inlet (a, cf. Figure 6) in the direction of the LCE is assumed to be in the form of cones, since the collimation of the rays of the solar simulator has a deviation of about $\pm 2^{\circ}$ (half angle). These cones are equally distributed on the ray inlet surface and are described by a cone axis and a cone angle. In the coordinate system shown in Figure 6, the cone axis (s) is described by Equation (22).

$$
s=\left(\begin{array}{c}
-\sin (\varphi) \\
\cos (\varphi) \sin (\psi) \\
-\cos (\varphi) \cos (\psi)
\end{array}\right)
$$

Here, $\varphi$ denotes the polar angle and $\psi$ the azimuth. For the experimentally investigated angles of incidence, the azimuth was $0^{\circ}$, so that Equation (22) can be simplified to Equation (23).

$$
\boldsymbol{s}_{\psi=0^{\circ}}=\left(\begin{array}{c}
-\sin (\varphi) \\
0 \\
-\cos (\varphi)
\end{array}\right)
$$




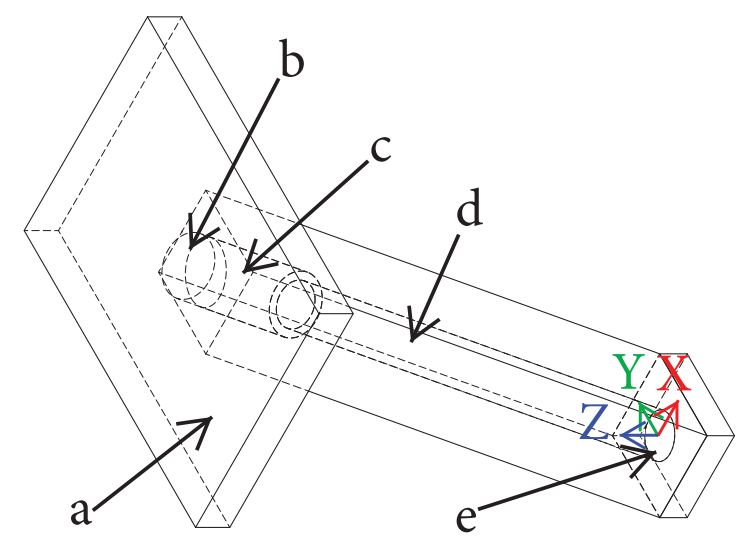

Figure 6. Domains of the SATIS model in state 3, which participate in the short-wave radiation transport.

Table 4. Applied boundary conditions for computing the short-wave radiation transport.

\begin{tabular}{lc}
\hline Notation & Boundary Condition \\
\hline a & Ray inlet \\
$\mathrm{b}$ & Material discontinuity; $\tau=0.9[33]$ \\
$\mathrm{c}$ & Wall; $\alpha=0.196$ (own measurement using an integrating sphere) \\
$\mathrm{d}$ & Wall; $\alpha=0.507$ (own measurement using an integrating sphere) \\
$\mathrm{e}$ & Wall; $\alpha=0.9[36]$ \\
\hline
\end{tabular}

The cone angle is twice the half collimation angle of the rays of the solar simulator, i.e., $4^{\circ}$. The area of the ray inlet (a) in Figure 6 amounts to $5 \mathrm{~cm} \times 3.6 \mathrm{~cm}$. A total of 2000 cones with 50 rays per cone ( 5556 rays $/ \mathrm{cm}^{2}$ ) were used to ensure that the computed results are independent of the number of rays. The power of each ray at the inlet ( $\left.\dot{Q}_{\text {ray,inlet }}\right)$ is calculated according to Equation (24).

$$
\dot{Q}_{\text {ray,inlet }}=\frac{I_{\mathrm{S}, \perp} A_{\text {inlet }}}{N_{\text {rays }}} \cos (\varphi) \cos (\psi)
$$

In Equation (24), $I_{\mathrm{S}, \perp}$ denotes the measured radiation intensity delivered by the solar simulator on a surface perpendicular to the direction of irradiation (cf. Table 2), $A_{\text {inlet }}$ the area of the ray inlet (a) and $N_{\text {rays }}$ the amount of released rays. The surfaces of the borosilicate glass cylinder protruding from the outside surface of the wall (b) are assigned with a transmittance of 0.9 [33]. At the material discontinuity between two materials of different refractive indices, Snell's law is used to reinitialize the wave vector. The surfaces on the outside of the wall (c), in the light-conducting element (d) and on the absorber plate (e) are provided with absorption coefficients of $0.196,0.507$ and 0.9. The rays that strike these opaque surfaces are reflected diffusely in all directions.

\section{Results and Discussion}

In the following subsections, the experimentally and numerically obtained effective thermal conductivities and angle-dependent total solar energy transmittances are presented.

\subsection{Effective Thermal Conductivity}

Table 5 shows the measured temperatures and heat fluxes on the inside $\left(T_{\text {IS }}, \dot{q}_{\text {IS }}\right)$ and outside $\left(T_{\mathrm{OS}}, \dot{q}_{\mathrm{OS}}\right)$ surfaces of SATIS for the manufacturing states 1,2 and 3 at the investigated temperature differences listed in Table 1. Furthermore, the effective thermal conductivities determined via Equations (1) and (3) are shown in this table. For state 1, the averaged effective thermal conductivity amounts to $(45 \pm 2) \frac{\mathrm{mW}}{\mathrm{mK}}$, which is in very good agreement with the value of $44 \frac{\mathrm{mW}}{\mathrm{mK}}$ [31], which was determined in this test bench on an overall wall structure by means of a parameter identification procedure. Compared to 
state 1, all measured effective thermal conductivities in state 2 are higher and an increase from $(48 \pm 3) \frac{\mathrm{mW}}{\mathrm{mK}}$ at the lowest temperature difference to $(50 \pm 2) \frac{\mathrm{mW}}{\mathrm{mK}}$ at the highest temperature difference can be observed in the experiments for $\lambda_{\text {eff }}$. In state 3 , according to Table 5, the averaged effective thermal conductivity is increased to $(57 \pm 2) \frac{\mathrm{mW}}{\mathrm{mK}}$ due to the incorporation of the borosilicate glass closure elements.

Table 5. Mean measured inside $\left(T_{\mathrm{IS}}, \dot{q}_{\mathrm{IS}}\right)$ and outside $\left(T_{\mathrm{OS}}, \dot{q}_{\mathrm{OS}}\right)$ surface temperatures and heat fluxes as well as calculated effective thermal conductivities for each manufacturing state of SATIS according to Equations (1) and (3).

\begin{tabular}{lccccc}
\hline SATIS State & $\boldsymbol{T}_{\text {IS }}$ in ${ }^{\circ} \mathrm{C}$ & $\boldsymbol{T}_{\mathrm{OS}}$ in ${ }^{\circ} \mathrm{C}$ & $\dot{\boldsymbol{q}}_{\text {IS }}$ in $\frac{\mathbf{W}}{\mathbf{m}^{2}}$ & $\dot{\boldsymbol{q}}_{\mathrm{OS}}$ in $\frac{\mathbf{W}}{\mathbf{m}^{2}}$ & $\lambda_{\text {eff }}$ in $\frac{\mathbf{m W}}{\mathbf{m ~ K}}$ \\
\hline 1—exp. 1 & 17.61 & 2.14 & 8.4 & 8.9 & 45 \\
1—exp. 2 & 21.46 & -2.30 & 13.2 & 13.7 & 45 \\
1-exp. 3 & 25.29 & -6.80 & 18.1 & 18.6 & 46 \\
\hline 2-exp. 1 & 17.47 & 2.07 & 9.0 & 9.3 & 48 \\
2-exp. 2 & 21.34 & -2.09 & 14.0 & 14.5 & 49 \\
2-exp. 3 & 25.15 & -6.47 & 19.5 & 19.8 & 50 \\
\hline 3-exp. 1 & 17.22 & - & 10.7 & - & $(57+57) / 2=57$ \\
3-exp. 2 & 20.88 & - & 16.4 & - & $(57+56) / 2=57$ \\
3-exp. 3 & 24.56 & - & 22.6 & - & $(58+57) / 2=58$ \\
\hline
\end{tabular}

The performed experiments show that the drilling of the stepped holes resulted in an increase in the averaged $\lambda_{\text {eff }}$ from $(45 \pm 2) \frac{\mathrm{mW}}{\mathrm{mK}}$ (state 1$)$ to $(49 \pm 3) \frac{\mathrm{mW}}{\mathrm{mK}}$ (state 2$)$. Due to those holes, heat transfer by convection and radiation may take place besides conduction. In the following, the relative contributions of the three heat transfer mechanisms on $\lambda_{\text {eff }}$ will be assessed by means of the developed numerical model from Section 2.3. To this aim, the SATIS model in state 2 is first simulated considering all heat transfer mechanisms (cond-conv-rad), then heat conduction and radiation (cond-rad) and finally only heat conduction (cond).

Figure 7 shows the experimentally (cf. Equation (1)) and numerically determined effective thermal conductivities of the SATIS prototype in state 2, where different heat transport mechanisms are taken into account in the simulation model. If all heat transport phenomena (cond-conv-rad) are included in the simulation model, numerically calculated effective thermal conductivities of $48.4 \frac{\mathrm{mW}}{\mathrm{mK}}, 48.5 \frac{\mathrm{mW}}{\mathrm{mK}}$ and $48.7 \frac{\mathrm{mW}}{\mathrm{mK}}$ are obtained for each $\Delta T_{\text {IC-OC }}$ from Table 1 , which agree very well with the experimentally determined $\lambda_{\text {eff }}$.

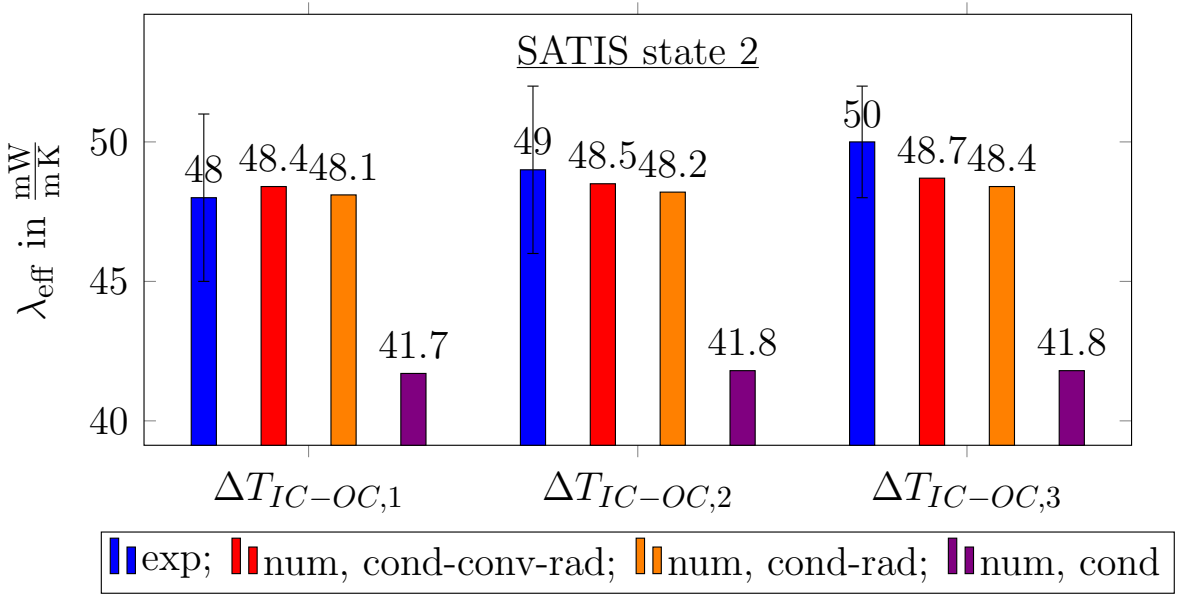

Figure 7. Experimentally (exp) and numerically (num) determined effective thermal conductivities $\left(\lambda_{\text {eff }}\right)$ of the SATIS panel in state 2 for the temperature differences listed in Table 1 taking into account the physical heat transport phenomena of heat conduction (cond), convection (conv) and thermal radiation (rad). 
Neglecting fluid motion within the LCE and considering only heat conduction and thermal radiation (cond-rad) results in a marginal reduction in $\lambda_{\text {eff }}$ of $0.3 \frac{\mathrm{mW}}{\mathrm{mK}}$ under all tested temperature differences. This can be attributed to the low inclination angle of the LCEs to the horizontal $\left(19^{\circ}\right)$ and the small diameters of the stepped holes $(8 \mathrm{~mm}$ and $6 \mathrm{~mm})$, resulting in the low absolute fluid velocities shown in Figure 8 for the highest $\Delta T_{\mathrm{IC}-\mathrm{OC}}$ from Table 1, which are lower than $3 \frac{\mathrm{mm}}{\mathrm{s}}$. Furthermore, neglecting thermal radiation and considering only thermal conduction (cond) would result in thermal conductivities of approximately $42 \frac{\mathrm{mW}}{\mathrm{mK}}$, which are rather low compared to the experiments. The relative contributions of conduction, radiation and convection in the effective thermal conductivity of the investigated state 2 sample amount to $86.2 \%, 13.2 \%$ and $0.6 \%$, respectively. Therefore, it can be concluded that thermal radiation must be considered besides conduction in the SATIS prototype.

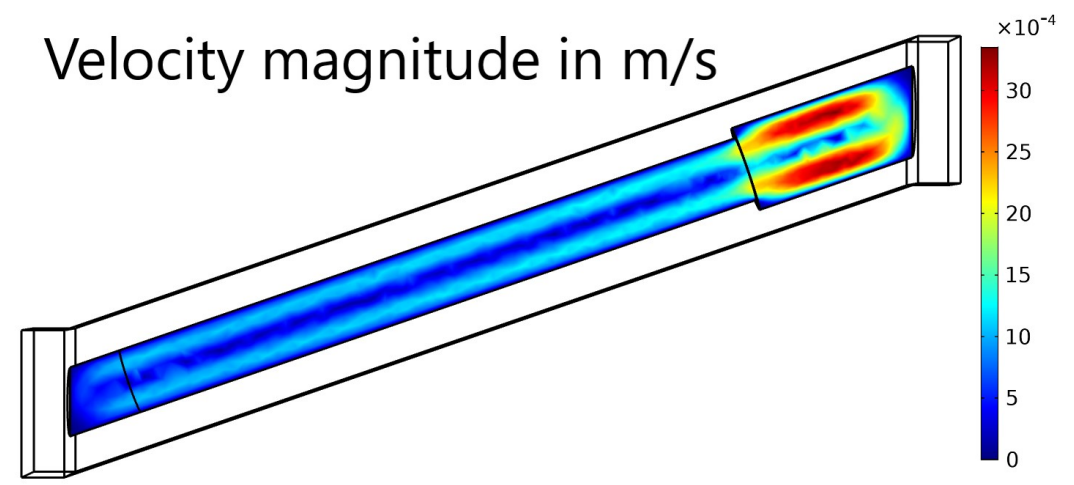

Figure 8. Velocity magnitude within the light-conducting element (LCE) in state 2 for the highest $\Delta T_{\text {IC }- \text { OC }}$ from Table 1.

The SATIS steady state thermal model in state 3 , which includes the closure elements made of borosilicate glass, shall also be validated. Here, only heat conduction and thermal radiation (cond-rad) were considered in the simulations, since natural convection had only a minor effect on $\lambda_{\text {eff }}$ as explained with state 2 . Moreover, the domain, where the highest absolute fluid velocities occurred with state 2 sample (cf. Figure 8 ) is no longer present in state 3 due to the incorporated glass cylinders. Figure 9 illustrates the experimentally (cf. Equation (3)) and numerically determined effective thermal conductivities for the SATIS prototype in state 3 . It is obvious that the incorporation of the closure elements resulted in an increase of the thermal conductivities from $48 \frac{\mathrm{mW}}{\mathrm{mK}}, 49 \frac{\mathrm{mW}}{\mathrm{mK}}$ and $50 \frac{\mathrm{mW}}{\mathrm{mK}}$ (state 2) to $57 \frac{\mathrm{mW}}{\mathrm{mK}}, 57 \frac{\mathrm{mW}}{\mathrm{mK}}$ and $58 \frac{\mathrm{mW}}{\mathrm{mK}}$ (state 3), since the glass, which has a thermal conductivity of $1.2 \frac{\mathrm{W}}{\mathrm{mK}}$ [33], acts as a thermal bridge and reduces the insulating effect of SATIS. As can be seen in the figure, there is a very good agreement between the experimental and computed $\lambda_{\text {eff }}$ for state 3 of the SATIS prototype. 


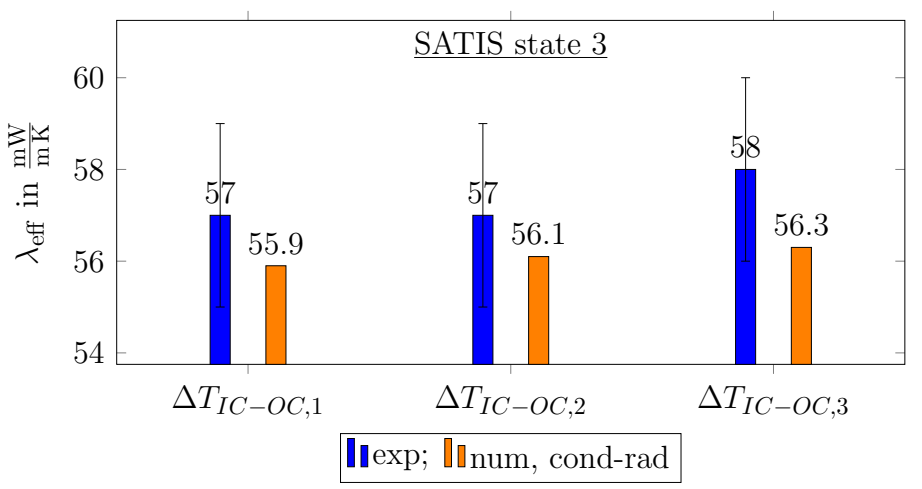

Figure 9. Experimentally (exp) and numerically (num) determined effective thermal conductivities $\left(\lambda_{\text {eff }}\right)$ of the SATIS panel in state 3 for the temperature differences listed in Table 1 taking into account the physical heat transport phenomena of heat conduction (cond) and thermal radiation (rad).

\section{Total Solar Energy Transmittance}

The computation of the total solar energy transmittance $(g)$ is performed in two steps. First, a ray-tracing simulation is carried out for each investigated solar angle of incidence. Here the radiation distribution and, derived from it, the heat fluxes on the outside surface of the wall and in the LCE are computed. Those heat fluxes $\left(\dot{q}_{b}\right)$ are regarded as constant and are used, according to Equation (15), in a second step as a boundary heat flux condition when computing the heat transport.

Figure 10 depicts both visually and quantitatively the computed ray power and the total boundary heat flow $\left(\dot{Q}_{\text {ray }}\right)$ in the light-conducting element for the solar angles of incidence of $19^{\circ}, 35^{\circ}$ and $60^{\circ}$. In addition to the total boundary heat flow, Figure $10 \mathrm{~b}, \mathrm{~d}, \mathrm{f}$ also show the dimensionless accumulated radiation distribution (DARD) along the z-axis in the light-conducting element, which is calculated according to Equation (25).

$$
\operatorname{DARD}(z)=\frac{\sum_{z=0 \mathrm{~m}}^{z} \dot{Q}_{\text {ray }}}{\sum_{z=0 \mathrm{~m}}^{0.08 \mathrm{~m}} \dot{Q}_{\text {ray }}}
$$

Comparing Figure 10a,c,e reveals that at an angle of incidence of $19^{\circ}$, more rays with higher ray power are conducted towards and absorbed by the black painted steel plate. At the solar incidence angles of $35^{\circ}$ and $60^{\circ}$, the rays which penetrate the borosilicate glass cylinder, primarily strike the surfaces adjacent to it. Some reflections take place inside the LCE, which causes individual rays to be directed towards the absorber. However, these rays are at considerably low energy levels compared to those at $19^{\circ}$, as can be seen in Figure 10a,c,e.

Figure $10 \mathrm{~b}, \mathrm{~d}, \mathrm{f}$ illustrate the total boundary heat flow ( $\left.\dot{Q}_{\text {ray }}\right)$ for the incidence angles of $19^{\circ}, 35^{\circ}$ and $60^{\circ}$. This heat flow is calculated from the absorbed power of all rays striking a specific surface element within the LCE. For an angle of $19^{\circ}$, two peak regions can be identified in Figure 10b. The first peak region belongs to the surface of the absorber, where a maximum boundary heat flow of $10.7 \mathrm{~mW}$ occurs. The second peak region is located in the transition zone where the stepped hole changes its diameter from $8 \mathrm{~mm}$ to $6 \mathrm{~mm}$. Here, the cross-sectional area of the light-conducting element is reduced by $44 \%$, so that a large number of rays, which penetrate the glass cylinder, hit the shoulder of the stepped hole. For the incidence angle of $35^{\circ}$ in Figure 10d, compared to the design angle of $19^{\circ}$, the total boundary heat flow near the absorber is already significantly reduced. In Figure 10f, for an incidence angle of $60^{\circ}$, almost all the ray power is absorbed by the surfaces adjacent to the borosilicate glass cylinder.

In Figure $10 \mathrm{~b}$, the DARD for the angle of $19^{\circ}$ indicates that $27 \%$ of the total ray power is absorbed by the absorber. Except in the region of the absorber and in the transition zone where the hole diameter decreases from $8 \mathrm{~mm}$ to $6 \mathrm{~mm}$, the DARD shows a nearly constant gradient, indicating that the surfaces in the LCE exhibit a nearly constant total boundary heat flow. In the transition zone, the DARD exhibits a step change from $71 \%$ to $94 \%$. For an 
angle of incidence of $60^{\circ}$, the DARD increases from 0.02 at $z=0.053 \mathrm{~m}$ to 1 at $z=0.08 \mathrm{~m}$, which corresponds to the outside surface of SATIS. This means that $98 \%$ of the ray power is absorbed by the surfaces adjacent to the borosilicate glass cylinder.

Figure 11 depicts the experimentally (cf. Equation (6)) and numerically determined total solar energy transmittances $(g)$ for the investigated angles of incidence $(\varphi)$ listed in Table 2. It can be seen that the maximum measured $g$ is located at the design angle of the SATIS prototype $\left(19^{\circ}\right)$ and amounts to $11.2 \%$. Starting from the design angle, the total solar energy transmittance decreases as the angle of incidence increases or decreases, and at the highest investigated angle of $60^{\circ}$, the experimentally determined $g$ only amounts to $2.9 \%$. The obtained $75 \%$ reduction in $g$ at high incidence angles proves that the main objective of the introduced SATIS proof-of-concept prototype is fulfilled; namely, to reach the maximum transmittance at a specified design angle (objective 1 in Section 2.1) and to very much reduce it at higher irradiation angles (objective 2 in Section 2.1) to lower summer overheating compared to TIMs [6].

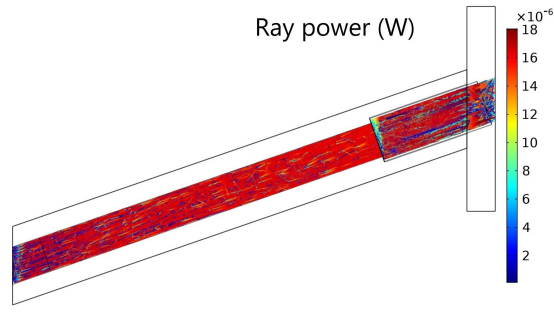

(a)

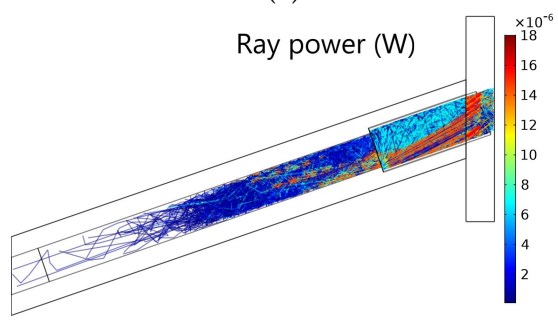

(c)

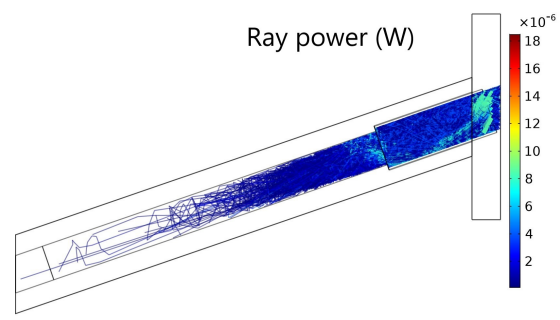

(e)

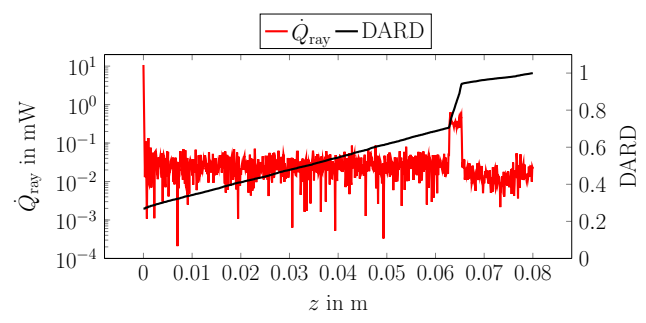

(b)

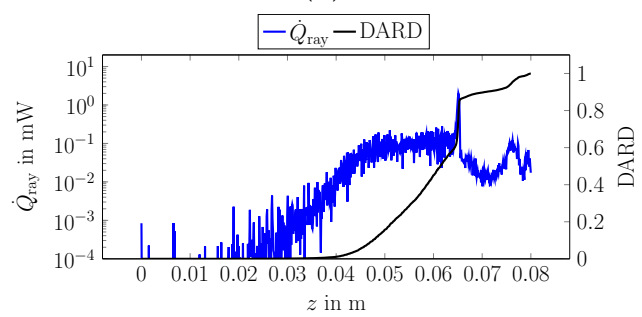

(d)

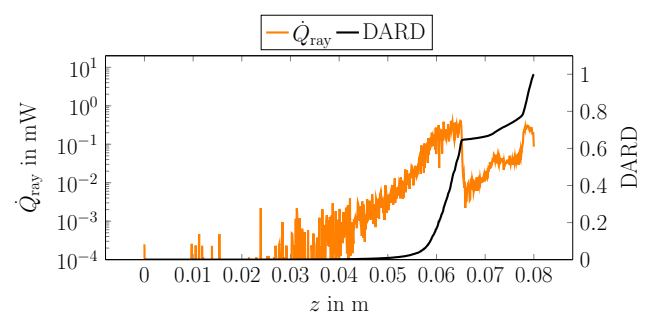

(f)

Figure 10. Ray power, total boundary heat flow $\left(\dot{Q}_{\text {ray }}\right)$ and dimensionless accumulated radiation distribution (DARD) within the LCE for the angles of incidence of $19^{\circ}, 35^{\circ}$ and $60^{\circ}$. (a) Ray power within the LCE for an angle of incidence of $19^{\circ}$. (b) Total boundary heat flow and dimensionless accumulated radiation distribution for an angle of incidence of $19^{\circ}$. (c) Ray power within the LCE for an angle of incidence of $35^{\circ}$. (d) Total boundary heat flow and dimensionless accumulated radiation distribution for an angle of incidence of $35^{\circ}$. (e) Ray power within the LCE for an angle of incidence of $60^{\circ}$. (f) Total boundary heat flow and dimensionless accumulated radiation distribution for an angle of incidence of $60^{\circ}$. 


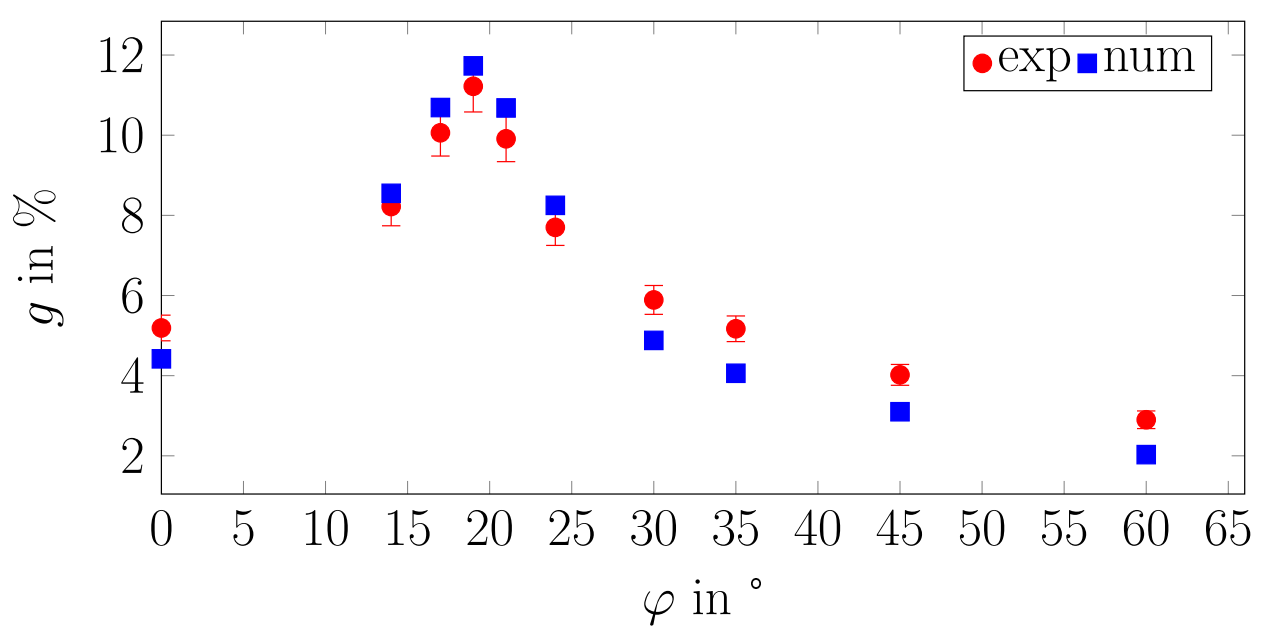

Figure 11. Experimentally (exp) and numerically (num) determined total solar energy transmittances $(g)$ for the angles of incidence $(\varphi)$ listed in Table 2.

Comparing the measured total solar energy transmittances of $14^{\circ}\left(8.2^{\circ}\right)$ and $24^{\circ}(7.7 \%)$, a difference in $g$ can be observed despite having the same distance of $5^{\circ}$ from the design angle. This phenomenon can also be observed in the simulations ( $8.6 \%$ vs. $8.2 \%)$ as well as for $17^{\circ}$ and $21^{\circ}$, although not that strongly pronounced. This is an indication that more solar radiation can enter the LCE at an angle of incidence below the design angle due to asymmetries, i.e., the inclined angle of the glass cylinder axis and the resulting higher fraction of the shell surface protruding at the bottom compared to the top of the cylinder (cf. Figure 1b). Particularly in the immediate vicinity of the design angle, the numerical model can reproduce the experimentally determined total solar energy transmittances in very good agreement, indicated by a low average deviation of only $5.6 \%$ between the experimental and numerical results in the range of $14^{\circ}$ to $24^{\circ}$. As can be seen in Figure 11, with increasing incidence angle, the simulation model underestimates $g$ for the investigated irradiation angles. This means that too little solar radiation is reaching the rear or too little heat by conduction or thermal radiation is transported to the absorber compared to the measurements. A possible reason could be the limited size of the simulation model (only one LCE) compared to the actual measurements.

As shown in the experiments, although the objective of having an angle-dependent total solar energy transmittance could be achieved, the incorporation of the light-conducting elements and, most specifically, the closure elements resulted in an increase in the effective thermal conductivity from $45 \frac{\mathrm{mW}}{\mathrm{mK}}$ (state 1 ) to $57 \frac{\mathrm{mW}}{\mathrm{mK}}$ (state 3 ), which imply a reduction in the net energy gain by SATIS because of the enhanced losses during off-shine periods. It is, therefore, our next development task to carry out an intensive parameter sensitivity analysis on all design parameters of SATIS in order to maximize the heat gain and, at the same time, minimize the effective thermal conductivity enhancement compared to the base material (objective 3 in Section 2.1). These results along with a year-wise simulation of a scaled-up optimized SATIS design under typical weathering conditions will be reported in our next communication.

\section{Conclusions}

In this paper, a newly-developed solar active insulation system (SATIS) to accomplish a highly-dependent total transmittance on the solar irradiation angle with the maximum being obtained at the desired design angle corresponding to the winter noon sun angle has been introduced. To this aim, light-conducting elements (LCEs) have been introduced into a mineral insulation base material to accomplish the targeted selectivity of the total solar transmittance. A proof-of-concept SATIS prototype has been built and investigated, both experimentally and numerically. A dedicated test facility incorporating a differential climatic chamber with separately controlled indoor and outdoor zones has been introduced. 
A solar simulator with adjustable radiation intensities and irradiation angles has been mounted inside the outdoor zone. COMSOL Multiphysics' models have been developed and validated against the experimental data. The main outcomes of the investigations are summarized below:

- A maximum total solar energy transmittance of $11.2 \%$ has been measured at the irradiation angle of $19^{\circ}$, which corresponds to a typical noon irradiation angle in wintertime in southern Germany.

- At an irradiation angle of $60^{\circ}$, representing summer conditions in central Europe, a total solar energy transmittance of $2.9 \%$ has been measured, which represents a reduction of $75 \%$ compared to the obtained value at $19^{\circ}$.

- The carried out ray tracing radiation simulations inside the LCEs has offered explanations for the obtained selectivity of the total transmittance. At an incidence angle of $19^{\circ}, 27 \%$ of the irradiated power is absorbed directly by the absorber surface at the backside of SATIS, while at the incidence angle of $60^{\circ}, 98 \%$ of the radiated power is absorbed by the surfaces adjacent to the glass cylinders, resulting in the remarkable reduction of the solar transmittance.

- The measured effective thermal conductivity of the base SATIS material amounts to $45 \frac{\mathrm{mW}}{\mathrm{mK}}$, which has been increased to $49 \frac{\mathrm{mW}}{\mathrm{mK}}$ and $57 \frac{\mathrm{mW}}{\mathrm{mK}}$ upon introducing the LCEs and then the closing elements out of borosilicate glass, respectively.

- The key parameters leading to the enhancement of the effective thermal conductivity of SATIS over that of the base material has been identified to be the length and the relatively high thermal conductivity of the applied closing elements in the investigated first SATIS prototype.

- The contribution of convection to the effective thermal conductivity of the SATIS prototype is proven to be negligible (below 1\%), which has been attributed to the small diameter and the low inclination of the LCEs to the horizontal $\left(19^{\circ}\right)$.

- On the other hand, thermal radiation contributes to $13 \%$ to the effective thermal conductivity of the SATIS prototype and cannot, therefore, be ignored.

The obtained results demonstrated very good validated numerical models, which will be applied, in our future work, to optimize the SATIS design and to assess its overall effect on reducing the heating demand in winter and the overheating potential in summer of real buildings under typical weathering conditions.

Author Contributions: Conceptualization, P.S. and B.D.; methodology, P.S. and B.D.; validation, P.S.; formal analysis, P.S., M.G., O.S. and B.D.; investigation, P.S.; data curation, P.S.; writing—original draft preparation, P.S.; writing-review and editing, M.G., O.S. and B.D.; visualization, P.S.; supervision, M.G., O.S. and B.D.; project administration, O.S. and B.D.; funding acquisition, O.S. and B.D. All authors have read and agreed to the published version of the manuscript.

Funding: This research has been funded by the German Federal Ministry of Economy and Energy in the project MAGGIE ("Energetische Modernisierung des genossenschaftlichen Wohnquartiers Margaretenau in Regensburg", funding code 03SBE0007A), which is gratefully acknowledged by the authors.

Institutional Review Board Statement: Not applicable.

Informed Consent Statement: Not applicable.

Data Availability Statement: The data presented in this study is available on request from the first author, P.S.

Acknowledgments: The authors would like to thank the Regensburg Center of Energy and Resources (RCER) of OTH Regensburg, the Technology and Science Network Oberpfalz (TWO) and the BayWISS Joint Academic Partnership "Energy" for their appreciated support.

Conflicts of Interest: The authors declare no conflict of interest. The funders had no role in the design of the study; in the collection, analyses, or interpretation of data; in the writing of the manuscript, or in the decision to publish the results. 


\section{References}

1. European Parliament and Council.Directive 2010/31/EU of the European Parliament and of the Council of 19 May 2010 on the Energy Performance of Buildings; European Parliament and Council: Brussels, Belgium, 2010.

2. Buildings Performance Institute Europe. 97\% of Buildings in the EU Need to Be Upgraded; Buildings Performance Institute Europe: Brussels, Belgium, 2017.

3. Buildings Performance Institute Europe. Future-Proof Buildings for All Europeans: A Guide to Implement the Energy Performance of Buildings Directive (2018/844); Buildings Performance Institute Europe: Brussels, Belgium, 2019.

4. European Parliament and Council. Directive (EU) 2018/844 of the European Parliament and of the Council of 30 May 2018 Amending Directive 2010/31/EU on the Energy Performance of Buildings and Directive 2012/27/EU on Energy Efficiency; European Parliament and Council: Brussels, Belgium, 2018.

5. Crawley, D.B.; Hand, J.W.; Kummert, M.; Griffith, B.T. Contrasting the capabilities of building energy performance simulation programs. Build. Environ. 2008, 43, 661-673. [CrossRef]

6. Wong, I.L.; Eames, P.C.; Perera, R.S. A review of transparent insulation systems and the evaluation of payback period for building applications. Sol. Energy 2007, 81, 1058-1071. [CrossRef]

7. Kaushika, N.D.; Sumathy, K. Solar transparent insulation materials: a review. Renew. Sustain. Energy Rev. $2003,7,317-351$. [CrossRef]

8. Sun, Y.; Wilson, R.; Wu, Y. A Review of Transparent Insulation Material (TIM) for building energy saving and daylight comfort. Appl. Energy 2018, 226, 713-729. [CrossRef]

9. Liang Wong, I.; Eames, P.; Perera, S. Energy simulations of a transparent insulated office facade retrofit in London, UK. Smart Sustain. Built Environ. 2012, 1, 253-276. [CrossRef]

10. Paneri, A.; Wong, I.L.; Burek, S. Transparent insulation materials: An overview on past, present and future developments. Sol. Energy 2019, 184, 59-83. [CrossRef]

11. Platzer, W.J. Bestimmung des solaren Energiegewinns durch Massivwände mit transparenter Wärmedämmung. Richtlinie Fachverbandes Transparente Wärmedämmung 2000. Available online: http:/ /www.umwelt-wand.de/twd/service/hilfen/richtlinie0 006.pdf (accessed on 16 March 2021).

12. Russ, C. Einsatz transparenter Wärmedämmung zur Gebäudesanierung. In Energie; Hoffmann, V.U., Thiele, R., Eds.; Vieweg+Teubner Verlag: Wiesbaden, Germany, 1994; Volume 3, pp. 82-94. [CrossRef]

13. Wittwer, V.; Platzer, W. Transparent thermal insulation materials and systems: State of the art and potential for the future. High Temp.-High Press. 2000, 32, 143-158. [CrossRef]

14. Čekon, M.; Slávik, R.; Zach, J. Experimental Analysis of Transparent Insulation Based on Poly-carbonate Multi-Wall Systems: Thermal and Optical Performance. Energy Procedia 2017, 132, 502-507. [CrossRef]

15. Platzer, W.J. Total heat transport data for plastic honeycomb-type structures. Sol. Energy 1992, 49, 351-358. [CrossRef]

16. Platzer, W.J. Solar transmission of transparent insulation material. Sol. Energy Mater. 1987, 16, 275-287. [CrossRef]

17. Symons, J.G. The Solar Transmittance of Some Convection Suppression Devices for Solar Energy Applications: An Experimental Study. J. Sol. Energy Eng. 1982, 104, 251-256. [CrossRef]

18. Platzer, W.J. Directional-hemispherical solar transmittance data for plastic honeycomb-type structures. Sol. Energy 1992, 49, 359-369. [CrossRef]

19. Kuhn, T.E. Calorimetric determination of the solar heat gain coefficient g with steady-state laboratory measurements. Energy Build. 2014, 84, 388-402. [CrossRef]

20. Świrska-Perkowska, J.; Kucharczyk, A.; Wyrwał, J. Energy Efficiency of a Solar Wall with Transparent Insulation in Polish Climatic Conditions. Energies 2020, 13, 859. [CrossRef]

21. Čekon, M.; Čurpek, J. A transparent insulation façade enhanced with a selective absorber: A cooling energy load and validated building energy performance prediction model. Energy Build. 2019, 183, 266-282. [CrossRef]

22. Čekon, M.; Čurpek, J. A Transparent Insulation Solar Façade Coupled with a Selective Absorber: An Experimentally Validated Building Energy Simulation Model. In Healthy, Intelligent and Resilient Buildings and Urban Environments; International Association of Building Physics (IABP): Syracuse, NY, USA, 2018; pp. 361-365. [CrossRef]

23. Sun, Y.; Liang, R.; Wu, Y.; Wilson, R.; Rutherford, P. Glazing systems with Parallel Slats Transparent Insulation Material (PS-TIM): Evaluation of building energy and daylight performance. Energy Build. 2018, 159, 213-227. [CrossRef]

24. Lien, A.G.; Hestnes, A.G.; Aschehoug, Ø. The use of transparent insulation in low energy dwellings in cold climates. Sol. Energy 1997, 59, 27-35. [CrossRef]

25. Manz, H.; Egolf, P.; Suter, P.; Goetzberger, A. TIM-PCM external wall system for solar space heating and daylighting. Sol. Energy 1997, 61, 369-379. [CrossRef]

26. Twidell, J.W.; Johnstone, C.; Zuhdy, B.; Scott, A. Strathclyde University's passive solar, low-energy, residences with transparent insulation. Sol. Energy 1994, 52, 85-109. [CrossRef]

27. Braun, P.O.; Goetzberger, A.; Schmid, J.; Stahl, W. Transparent insulation of building facades—Steps from research to commercial applications. Sol. Energy 1992, 49, 413-427. [CrossRef]

28. Berardi, U. The development of a monolithic aerogel glazed window for an energy retrofitting project. Appl. Energy 2015, 154, 603-615. [CrossRef] 
29. Franken Maxit GmbH. maxit eco 72. 2020. Available online: https://docs.maxit.de:8443/procat/assets/images/TM-DEGEECO72.pdf (accessed on 16 March 2021).

30. Lehmann, S.; Schwinger, L.; Scharfe, B.; Gerdes, T.; Ehrhardt, M.; Riechert, C.; Fischer, H.B.; Schmidt-Rodenkirchen, A.; Scharfe, F.; Wolff, F. Mikro-Hohlglaskugeln als Basis energieeffizienter Dämmung von Gebäuden. In Beiträge der Konferenz für neue Materialien im Bauwesen am 31. Januar 2018 in Berlin; Deutscher Ausschuss für Stahlbeton e.V., Ed.; Fraunhofer IRB Verlag: Berlin, Germany, 2018; pp. 21-25.

31. Steininger, P.; Gaderer, M.; Dawoud, B. Experimental and numerical study on the solar gain and heat loss of typical existing and refurbished German buildings. iCRBE Procedia 2020, 1, 75-93. [CrossRef]

32. Franken Maxit GmbH. maxit Siliconharzfarbe A 7030. 2020. Available online: https://docs.maxit.de:8443/procat/assets/images/ TM-DE-FDSILICOFA\%20A.pdf (accessed on 16 March 2021).

33. Schott AG. DURAN ${ }^{\circledR}$ : Tubing, Rods and Capillaries Made of Borosilicate Glass 3.3. 2016. Available online: https://www.schott. com/d/tubing/66ee849c-cad9-42a3-97cb-67fd0534e3fb/schott_duran_brochure_gb_final.pdf (accessed on 16 March 2021).

34. DIN Deutsches Institut für Normung e.V. Fundamentals of Metrology_Part 3: Evaluation of Measurements of a Single Measurand, Measurement Uncertain-ty; DIN1319-3; DIN Deutsches Institut für Normung e.V.: Berlin, Germany, 1996; [CrossRef]

35. Fachverband Transparente Wärmedämmung e.V. Transparente Wärmedämmung: Planerische Grundlagen und Hinweise. Available online: http:/ / www.umwelt-wand.de/twd/service/infos/info3.pdf (accessed on 16 March 2021).

36. Baehr, H.D.; Stephan, K. Wärme- und Stoffübertragung, 8th ed.; Springer: Berlin/Heidelberg, Germany, 2013.

37. COMSOL. Material Library User's Guide; COMSOL: Stockholm, Sweden, 2018. Available online: https://doc.comsol.com/5.4/ doc/com.comsol.help.matlib/MaterialLibraryUsersGuide.pdf (accessed on 16 March 2021).

38. COMSOL. Ray Optics Module User's Guide; COMSOL: Stockholm, Sweden, 2018. Available online: https://doc.comsol.com/5.4/ doc/com.comsol.help.roptics/RayOpticsModuleUsersGuide.pdf (accessed on 16 March 2021).

39. Landau, L.D.; Lifšic, E.M. The Classical Theory of Fields, 4th ed.; Pergamon International Library of Science: Oxford, UK; Technology: New York, NY, USA; Engineering: Toronto, ON, Canada; Social Studies: Sydney, Australia; Pergamon Press: Braunschweig, Germay, 1975. 